\title{
Utilização do método GUT para avaliação de manifestações patológicas em edificações escolares do Oeste do Rio Grande do Norte
}

\author{
R. Santos ${ }^{1 *}$, A. Queiroz ${ }^{1}$, G. Albuquerque ${ }^{1}$, C. Cruz $^{2}$ \\ *Autor de Contato: rodrigorodrigues9798@hotmail.com \\ ${ }^{1}$ Graduando em Engenharia Civil pela Universidade Potiguar, Brasil. \\ ${ }^{2}$ Doutora em Física da Matéria Condensada e Docente da Universidade Potiguar, Brasil.
}

\begin{abstract}
RESUMO
A incidência de manifestações patológicas em edificações então presentes nas mais diversas fases e tipos de construções. O objetivo desse artigo é analisar as principais manifestações patológicas em três edificações escolares do Oeste do Rio Grande do Norte, utilizando o método GUT para priorização dessas anomalias. Foi realizada uma revisão bibliográfica na literatura, visitas in loco com inspeção visual, registros fotográficos e, em seguida, foram analisados os dados quantitativos através da metodologia da matriz GUT Gravidade, Urgência e Tendência. Verificou-se a presença de diversas manifestações patológicas nos objetos em estudo. Concluiu-se também que utilização da ferramenta matriz GUT foi satisfatória no auxílio à tomada de decisão quanto às atividades de manutenção e recuperação.
\end{abstract}

Palavras clave: Manifestações patológicas, métodos de avaliação, recuperação, GUT.

\begin{abstract}
The incidence of pathological manifestations in buildings then present in the most
\end{abstract}


diverse phases and types of constructions. The objective of this article is to analyze the main pathological manifestations in three school buildings in the west of Rio Grande do Norte State, using the GUT method to prioritize these anomalies. It was performed a literature review, site visits with visual inspection, photographic records and then the quantitative data were analyzed through the GUT matrix methodology - Gravity, Urgency and Tendency. It was verified the presence of several pathological manifestations in the objects under study. It was also concluded that the use of the GUT matrix tool was satisfactory in helping the decision making process regarding maintenance and repair activities.

Keywords: pathological manifestations, assessment methods, recovery, GUT.

\section{RESUMEN}

La incidencia de las manifestaciones patológicas en los edificios se presenta entonces en las más diversas fases y tipos de construcciones. El objetivo de este artículo es analizar las principales manifestaciones patológicas en tres edificios escolares del oeste de Rio Grande do Norte, utilizando el método GUT para priorizar estas anomalías. Se realizó una revisión bibliográfica, visitas in situ con inspección visual, registros fotográficos y luego se analizaron los datos cuantitativos a través de la metodología de la matriz GUT - Gravedad, Urgencia y Tendencia. Se comprobó la presencia de varias manifestaciones patológicas en los objetos estudiados. También se llegó a la conclusión de que el uso de la herramienta de la matriz GUT era satisfactorio para ayudar a la toma de decisiones sobre las actividades de mantenimiento y recuperación.

Palabras clave: manifestaciones patológicas, métodos de evaluación, recuperación, GUT.

\section{INTRODUÇÃO}

A incidência de manifestações patológicas em edificações então presentes nas mais diversas fases e tipos de construções. Segundo Santos et. al (2014), a deterioração é um processo que tem surgimento não somente com a conclusão e entrega da obra ao cliente, mas pode ter aparição antes 
da conclusão também. O seu surgimento se dá de forma variada e é de conhecimento e ocorrência em todo o mundo, variando os tipos de acordo com o ambiente, com a forma de execução e materiais utilizados. De acordo com Queiroz et. al (2020), as principais causas da ocorrência das manifestações patológicas nas edificações são devido a dois pontos, sendo eles a falta de um devido plano de manutenção ou até mesmo dessas manutenções serem realizadas de maneira inadequada.

É habitual que as manifestações patológicas tenham sua intensificação com o tempo, com isso é necessária sua identificação e classificação para que rapidamente sejam corretam tratadas, pois caso não ocorra a devida correção pode ocasionar danos variando de magnitude baixas e graves, podendo ocorrer até o colapso das estruturas (BRAGA el.al, 2019).

De acordo com cada método construtivo, material e forma de execução os tipos e causas das manifestações patológicas podem variar, como por exemplo, fissuras, trincas, desplacamento, desagregação e pulverulência, eflorescência, morfo e bolor, entre outros, nos quais possuem suas possíveis causas e correções adequadas (FRANÇA et. al, 2011; JONOV et. al, 2013).

As manifestações patológicas das construções não acontecem de forma independente e sem razão, geralmente tem motivo relacionado a algum erro cometido ainda no processo de concepção, sendo valioso o conhecimento da origem do problema e o retrato da construção para que se possa descobrir o que aconteceu para gerar determinado problema patológico (HELENE, 2003).

Dessa forma, metodologias são estudadas e desenvolvidas para auxiliarem na identificação das anomalias e possíveis correções. Um deles é o método de Matriz GUT - Gravidade, Urgência e Tendência, que possui variantes de gravidade $(\mathrm{G})$ que representa a potência da manifestação patológica, urgência $(\mathrm{U})$ define o nível do problema a ser resolvido e tendência $(\mathrm{T})$ a evolução em que o problema está tendo, com ele é possível obter informações importantes para definições de decisões a serem tomadas, as avaliações são obtidas por meio de números (FÁVERI e SILVA, 2016; BRAGA el.al, 2019).

Dada a importância do tema, a presente pesquisa tem o objetivo identificar, classificar e analisar os principais dados das manifestações patológicas presentes em três edificações escolares utilizando a metodologia da matriz GUT.

\section{METODOLOGIA}

No presente artigo foram identificadas e analisadas manifestações patológicas de três escolas do estado do Rio Grande do Norte. A primeira está localizada no município de Ipanguaçu e que para o presente estudo foi nomeada de A, já a segunda e a terceira estão localizadas no município de Mossoró e foram nomeadas de $\mathrm{B}$ e $\mathrm{C}$, respectivamente. Para tanto a metodologia foi dividida em 4 etapas, conforme ilustrado na Figura 1.

Figura 1: Metodologia utilizada no estudo

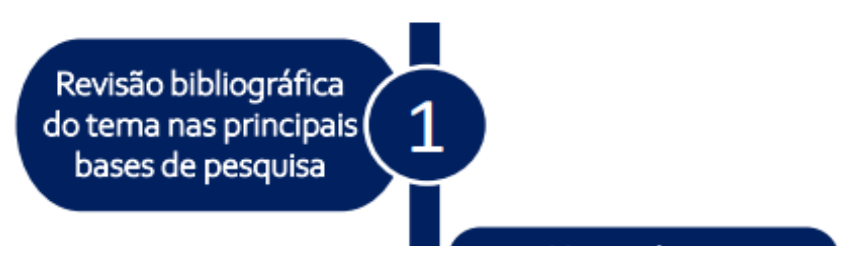

XVI Congreso Latinoamericano de Patología de la Construcción 
Foi realizada a revisão da literatura acerca do tema. Na sequência, foram realizadas visitas in loco nas escolas A, B e C para identificar visualmente, registrar e catalogar as principais manifestações patológicas encontradas nas estruturas.

Tabela 1: Matriz GUT

\begin{tabular}{|c|c|c|c|c|}
\hline \multirow{2}{*}{ Pontos } & Gravidade & Urgência & Tendência & A \\
\cline { 2 - 5 } & $\begin{array}{c}\text { Prejuizos de nenhuma } \\
\text { decisão ser tomada }\end{array}$ & $\begin{array}{c}\text { Necessidade de } \\
\text { tomada de decisão }\end{array}$ & $\begin{array}{c}\text { Evolução do problema caso } \\
\text { nenhuma decisão seja tomada }\end{array}$ & Agravamento imediato \\
\hline $\mathbf{5}$ & Extremamente graves & Imediatamente & $5 \times 5 \times 5=125$ \\
\hline $\mathbf{4}$ & Muito Graves & Urgentemente & Agravamento a curto prazo & $4 \times 4 \times 4=64$ \\
\hline $\mathbf{3}$ & Graves & $\begin{array}{c}\text { O quanto antes } \\
\text { possivel }\end{array}$ & Agravamento em médio prazo & $3 \times 3 \times 3=27$ \\
\hline $\mathbf{2}$ & Pouco Graves & Mediana & Agravamento em longo prazo & $2 \times 2 \times 2=8$ \\
\hline $\mathbf{1}$ & Sem gravidade & Pouca & Não há indicios de que irá se & $1 \times 1 \times 1=1$ \\
\hline
\end{tabular}

Fonte: Autores

A terceira etapa consistiu na aplicação da metodologia da matriz GUT (Gravidade, Urgência e Tendência) para classificação das manifestações patológicas, como visto Tabela 1.

A metodologia da Matriz GUT - Gravidade, Urgência e Tendência, também é conhecida como Matriz de Prioridades, a qual auxilia na priorização de resolução de problemas. De acordo com Daychoum (2012) no critério Gravidade são classificados os efeitos em caso de nenhuma providência ser tomada acerca do problema; já no quesito Urgência avalia-se o quão necessário se faz tomar uma decisão para resolver o problema encontrado, e no critério Tendência pode ser avaliada a evolução que pode acontecer com o problema encontrado. Cada critério para avaliação da matriz GUT recebe uma pontuação de 1 a 5 , onde 1 é menos grave e 5 mais grave, sendo o resultado a multiplicação da pontuação atribuída a cada um dos critérios. Segundo Braga et al. (2019) a metodologia GUT é de extrema importância e utilidade para resolução de problemas, visto que é possível classificar os problemas encontrados de acordo com sua gravidade e assim traçar as melhores estratégias para solução. 


\section{RESULTADOS}

\subsection{Escola A}

\subsubsection{Levantamento das manifestações patológicas}

Para a escola intitulada como A, situada na cidade de Ipanguaçu, foram encontradas manifestações patológicas em sua maioria na parte externa da edificação, em específico nos revestimentos e pinturas, possivelmente ocasionados por má execução e/ou emprego de materiais de baixa qualidade. Na Figura 2 é possível perceber que o reboco tem uma aparência arenosa e encontra-se parcialmente exposto e, que pode ter sido uma das causas para acontecimento da manifestação patológica em questão.

Figura 2: Reboco exposto

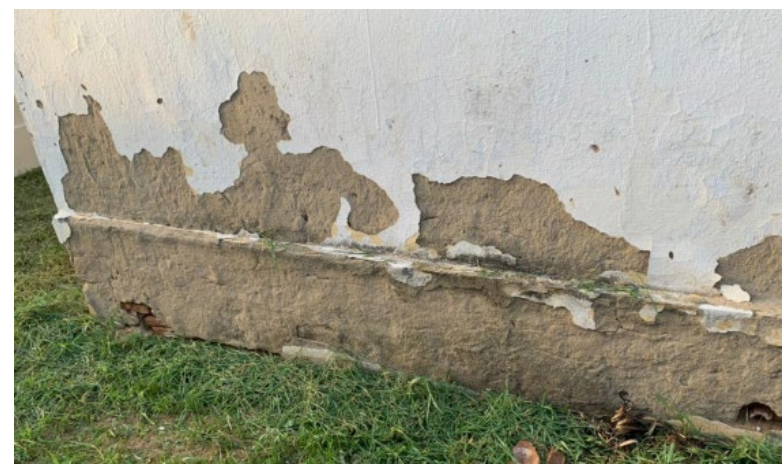

Fonte: Autores, 2021

Na Figura 3 nota-se um agravamento da situação anteriormente encontrada, na qual a exposição vai além do reboco, atingindo os blocos cerâmicos, possivelmente ocasionados pelos mesmos motivos.

Figura 3: Blocos cerâmicos expostos

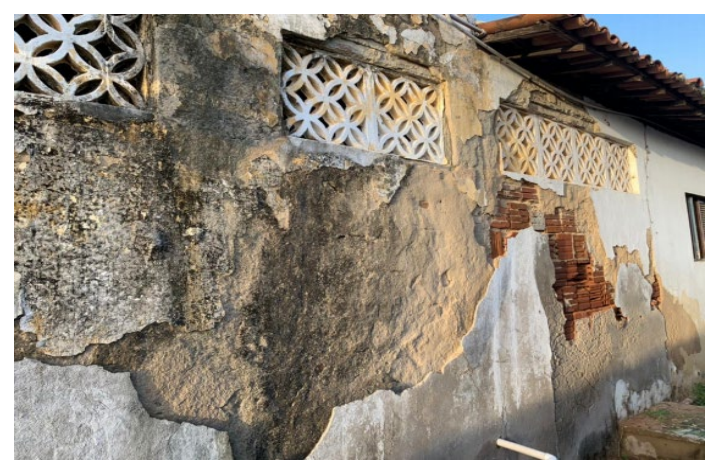

Fonte: Autores, 2021

Na Figura 4 percebe-se a degradação da pintura, possivelmente ocasionado pela presença de agente biológicos decorrente de infiltrações, visto que a presença das tubulações sugere que seja uma área da edificação em constante contato com umidade e/ou água.

Figura 4: Degradação da pintura

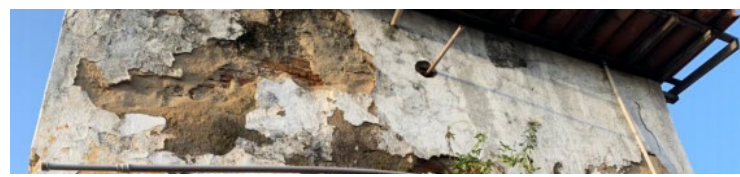


Na Figura 5 nota-se uma degradação parcial da pintura das paredes, possivelmente ocasionada pela ausência de destinação de águas pluviais, na qual provavelmente entram em contato com as paredes em períodos chuvosos, causando assim as manifestações patológicas encontradas.

Figura 5: Degradação das paredes

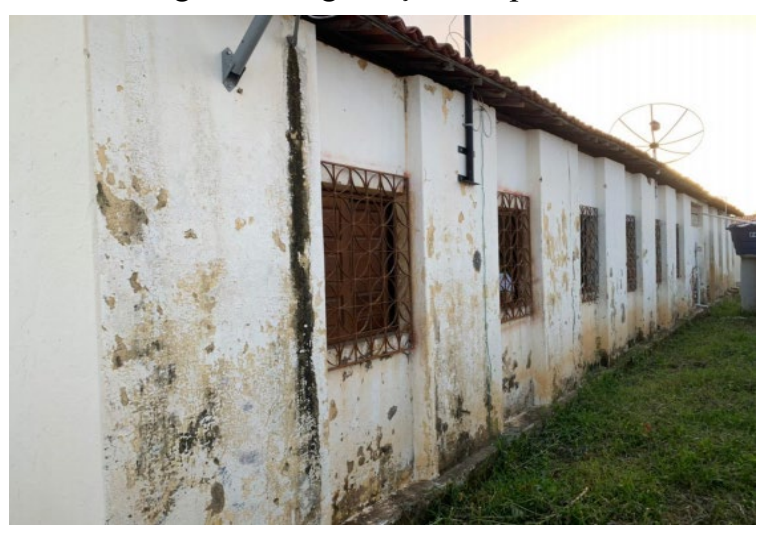

Fonte: Autores, 2021

\subsubsection{Avaliação utilizando o método GUT}

Tabela 2 - Matriz GUT 


\begin{tabular}{|c|c|c|c|c|c|c|}
\hline Escola & Foto & Descrição & G & U & T & GUT \\
\hline A & 2 & Desagregação da pintura & 3 & 4 & 3 & 36 \\
\hline A & 3 & $\begin{array}{c}\text { Desagregação da pintura e do reboco com exposição dos } \\
\text { blocos cerámicos }\end{array}$ & 5 & 4 & 4 & 80 \\
\hline A & 4 & $\begin{array}{c}\text { Desagregação da pintura e com presença de agentes } \\
\text { biológicos causando mofo/bolor }\end{array}$ & 5 & 4 & 4 & 80 \\
\hline A & 5 & $\begin{array}{c}\text { Presença de agentes biológicos causando mofo/bolor e } \\
\text { inicio da desagregação da pintura }\end{array}$ & 2 & 3 & 3 & 18 \\
\hline
\end{tabular}

Conforme ilustrado na Tabela 2, foi realizada a avaliação e classificação das manifestações patológicas utilizando a metodologia da matriz GUT, sendo as anomalias das Figuras 3 e 4 as que somaram mais pontos (80) e que necessitam de uma tomada de decisão e/ou intervenção para reparo da região afetada. As demais manifestações patológicas avaliadas necessitam de reparos de caráter preventivo, de modo a corrigir os problemas encontrados e impedir sua evolução, evitando assim maiores danos e prejuízos de ordem financeira.

\subsection{Escola B}

\subsubsection{Levantamento das manifestações patológicas}

Para a escola intitulada como B, situada na cidade de Mossoró, foram encontradas manifestações patológicas de diversos tipos e em vários ambientes da edificação, em mais evidência nos revestimentos, pinturas e exposição da armadura, podendo ter a ocorrência devido à má execução e/ou emprego de materiais de baixa qualidade, além de uma possível não realização de manutenções necessárias antes do surgimento de tais anomalias. Na Figura 6 é possível perceber o desplacamento do revestimento do pilar, que pode trazer diversos problemas a estruturas e comprometer a estabilidade.

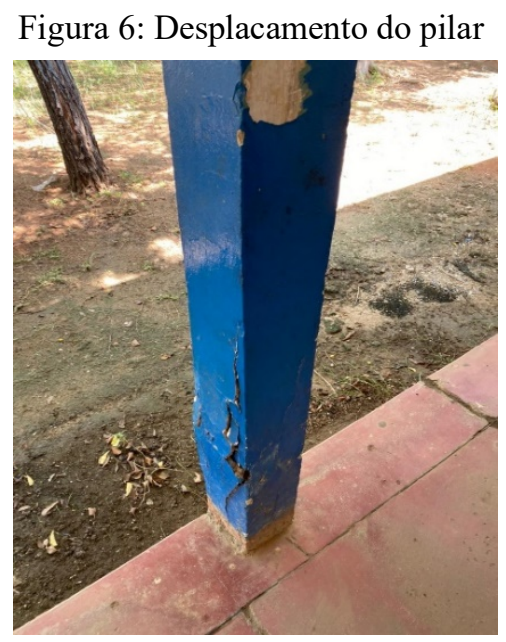

Fonte: Autores, 2021

Nas Figuras 7 e 8 é possível observar o surgimento de morfo e bolor, além da degradação da pintura presente do teto e parede, sendo possivelmente causados por infiltrações e surgimento de agentes biológicos.

Figura 7: Mofo e degradação da pintura no teto

Figura 8: Mofo/ bolor no teto e parede
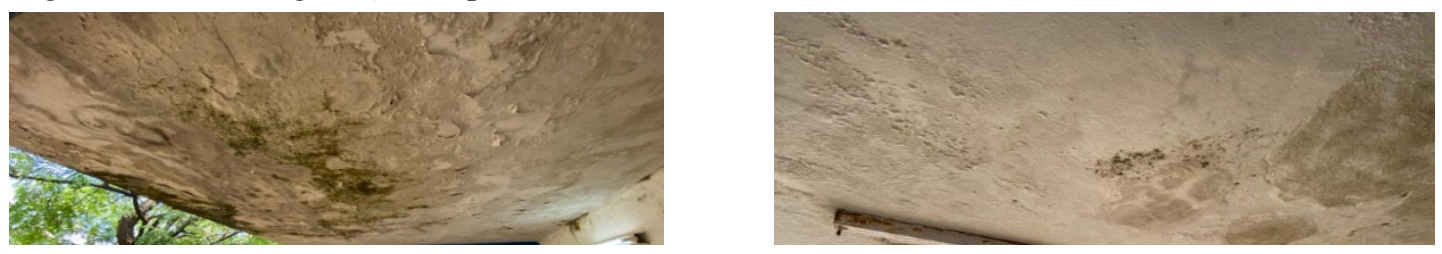

XVI Congreso Latinoamericano de Patología de la Construcción 
Na Figura 9 é possível observar armaduras expostas devido a degradação do revestimento, além de degradação da pintura, sendo possivelmente causado por má execução do cobrimento das armaduras.

Figura 9: Armaduras expostas no teto

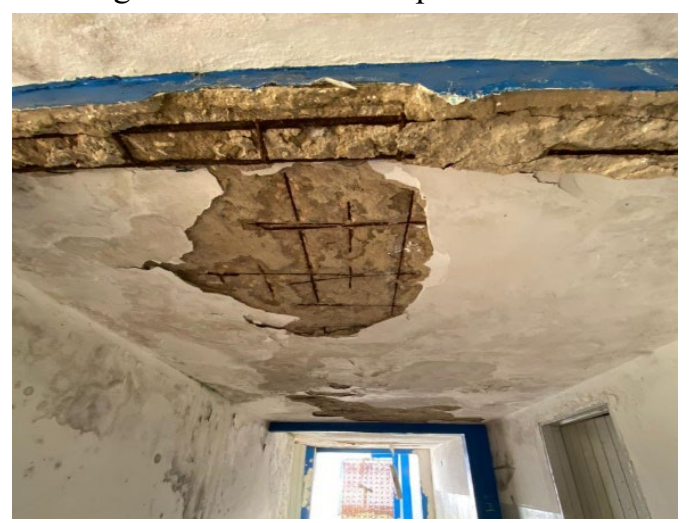

Fonte: Autores, 2021

\subsubsection{Avaliação utilizando o método GUT}

$\mathrm{Na}$ Tabela 3, foi realizada a avaliação e classificação das manifestações patológicas utilizando a metodologia da matriz GUT, sendo as manifestações patológicas das Figuras 6 e 9 as que somaram uma pontuação mais alta (125) e que necessitam de uma tomada de decisão imediatamente para reparo da região afetada, por apresentar grandes riscos a estabilidade da estrutura. A anomalia das Figuras 7 e 8 foi a segunda com maior pontuação de acordo com a metodologia utilizada (36), se fazendo necessária uma intervenção urgentemente, visto que se encontra em estágio de degradação bem acentuada, podendo provocar até outras manifestações patológicas, e sua evolução pode ser rápida e trazer riscos a estabilidade da estrutura e a segurança dos usuários.

Tabela 3: Análise das manifestações patológicas

\begin{tabular}{|c|c|c|c|c|c|c|}
\hline Escola & Foto & Descrição & G & U & T & GUT \\
\hline B & 6 & Desplacamento do revestimento do pilar & 5 & 5 & 5 & 125 \\
\hline B & 7 & Desagregação da pintura/mofo e bolor & 3 & 4 & 3 & 36 \\
\hline B & 8 & Desagregação da pintura/mofo e bolor & 3 & 4 & 3 & 36 \\
\hline
\end{tabular}


\begin{tabular}{l|l|l} 
B & 9 & Exposição da armadura \\
\hline
\end{tabular}

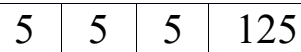

Fonte: Autores, 2021.

\subsection{Escola C}

\subsubsection{Levantamento das manifestações patológicas}

$\mathrm{Na}$ escola intitulada como $\mathrm{C}$, situada na cidade de Mossoró, foram encontradas manifestações patológicas em sua maioria na parte interna da edificação, em específico nas estruturas, possivelmente ocasionados por má execução e/ou emprego de materiais de baixa qualidade.

Nas Figuras 10 e 11 nota-se uma degradação da pintura das paredes e o reboco e armadura encontra-se exposto do pilar, devido provavelmente a infiltração da umidade.

Figura 10: Reboco e armação exposta

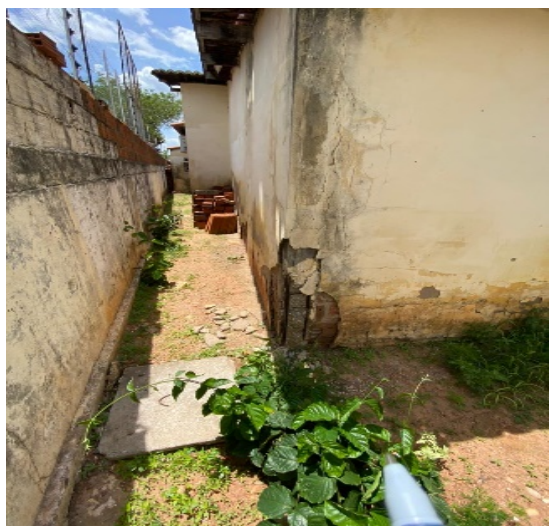

Fonte: Autores, 2021
Figura 11: Degradação da parede

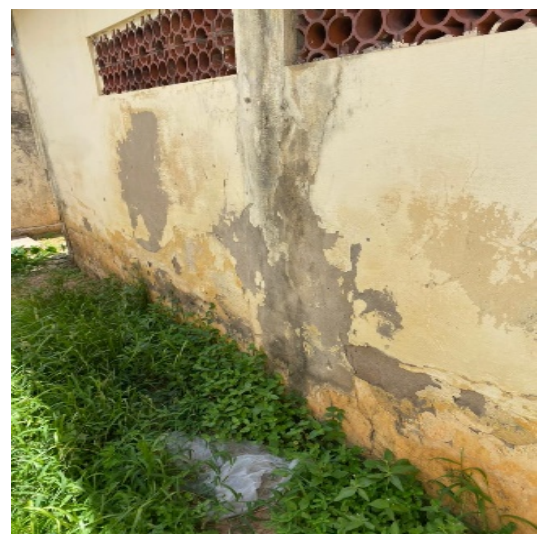

Fonte: Autores, 2021

Na Figura 12 é possível observar a degradação da estrutura de concreto do poste em questão, deixando a armadura exposta, passível de oxidação.

Figura 12: Degradação do poste

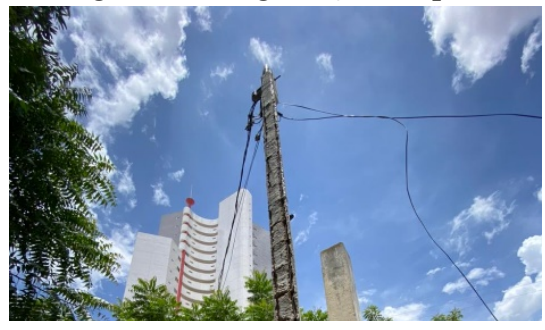

XVI Congreso Latinoamericano de Patología de la Construcción 


\subsubsection{Avaliação utilizando o método GUT}

Tabela 4: Análise das manifestações patológicas

\begin{tabular}{|c|c|c|c|c|c|c|}
\hline Escola & Foto & Descrição & G & U & T & GUT \\
\hline C & 10 & $\begin{array}{c}\text { Degradação da pintura das paredes e o reboco, com } \\
\text { armadura do pilar exposta. }\end{array}$ & 4 & 3 & 2 & 24 \\
\hline C & 11 & Degradação da pintura das paredes e o reboco & 4 & 3 & 2 & 24 \\
\hline C & 12 & Degradação da armadura & 5 & 5 & 4 & 100 \\
\hline
\end{tabular}

Fonte: Autores, 2021.

Como visto Tabela 4, foi realizada a avaliação e classificação das manifestações patológicas utilizando a matriz GUT, sendo as manifestações patológicas da figura 16 a que soma mais pontos (100) e que necessita de uma tomada de decisão e/ou intervenção para reparo da região afetada. As demais manifestações patológicas avaliadas necessitam de reparos de caráter preventivo, de modo a corrigir os problemas encontrados e impedir sua evolução, evitando assim maiores danos e prejuízos de ordem financeira.

\section{CONCLUSÕES}

Com a importância do tema em questão e com a observação do grande número de manifestações patológicas encontrada na região, conclui-se que as manifestações mais comuns e presentes nas 3 (três) escolas é a degradação da pintura causadas possivelmente pela presença de mofo/bolor. Além disso, foram encontradas manifestações patológicas de extrema gravidade e reparo imediato como apresentado na escola $\mathrm{B}$ e $\mathrm{C}$.

$\mathrm{Na}$ escola $\mathrm{A}$, foram encontradas manifestações patológicas em sua maioria na parte externa da edificação, em específico nos revestimentos e pinturas. Na escola B foram encontradas a presença dessas manifestações patológicas e em mais evidência nos revestimentos, pinturas e exposição da armadura. Já, na escola $\mathrm{C}$, a maioria das manifestações patológicas estava presente na parte interna da edificação, com presença de fissuras, mofo/bolor e exposição da armadura.

Concluímos que a aplicação da metodologia da matriz GUT para fins de gerenciamento possibilitou uma avaliação quantitativa dos problemas patológicos encontrados nas edificações educacionais e permitiu a mensuração da gravidade desses, bem como, o grau de priorização das ações corretivas e preventivas para possível correção dos problemas.

\section{REFERÊNCIAS}


Braga, I. C., Brandão, F. S., Ribeiro, F. R. C., Diógenes, A. G. (2019), “Aplicação da Matriz GUT na análise de manifestações patológicas em construções históricas”, Revista ALCONPAT, 9(3), pp. 320 - 335, DOI: http://dx.doi.org/10.21041/ra.v9i3.400.

Daychoum, Merhi. 40+20 ferramentas e técnicas de gerenciamento. Brasport, 2018.

Fáveri, Rafael; Silva, Alexandre. Método GUT aplicado à gestão de risco de desastres: uma ferramenta de auxílio para hierarquização de riscos. Revista Ordem Pública, v. 9, n. 1, p. 93-107, 2016.

França, A. A., Marcondes, C. G. N., Rocha, F. C. D., Medeiros, M. H. F. D. e Helene, P. R. Patologia das construções: uma especialidade na engenharia civil. Téchne, São Paulo, v. 19, n. 174, p. 72-77, 2011.

Helene, Paulo R. Do Lago. Manual de reparo, proteção e reforço de estruturas de concreto. São Paulo, Red Rehabilitar, 2003.

Jonov, Cristiane Machado Parisi; Nascimento, Nilo De Oliveira; Silva, Adriano de Paula. Avaliação de danos às edificações causados por inundações e obtenção dos custos de recuperação. Ambiente Construído, v. 13, n. 1, p. 75-94, 2013.

Nazario, Daniel. Manifestações das patologias construtivas nas edificações públicas da rede municipal de Criciúma: Inspeção dos sete postos de saúde. 2012.

Queiroz, A. B. R., Marques, M. V. D., Santos, K. F., Cruz, C. P. T., Santos, R. R. e Lucena, M. D. (2020). Análise de manifestações patológicas na balaustrada da av. Getúlio Vargas em natal/rn: um estudo de caso. Congresso brasileiro de patologia das construções - CBPAT. Fortaleza- CE, p. 1724-1730.

Santos, W. J. D., Dardengo, C. F. R., Carvalho, C. C., Alvarenga, R. D. C. S. S., Silva, R. C. D. Prescrições para construções de edificações residenciais multifamiliares com base nas patologias identificadas na cidade de Viçosa-MG. Revista de Engenharia e Tecnologia, v. 6, n. 2, p. Páginas 104-123, 2014. 